\title{
Role of the Matching Familiar Figures Test-20 in the Analysis of Theoretical Validity of the Reflection-Impulsivity: A Study with Personality
}

\author{
Aportación del Matching Familiar Figures Test-20 al análisis de la validez teórica de la \\ Reflexividad-Impulsividad: un estudio con la personalidad
}

\author{
Hugo Carretero-Dios, Macarena de los Santos-Roig y Gualberto Buela-Casal \\ Universidad de Granada, España
}

\begin{abstract}
The present study analyzes the theoretical validity of the cognitive style reflection-impulsivity with an approach based on cognition. For this purpose, it is explored the relationship between personality and reflection-impulsivity. The Matching Familiar Figures Test 20, MFFT-20 (Cairns \& Cammock, 1978) was used. This test has not been employed in previous investigations with the same goal. However, the MFFT-20 has proved to be the most reliable test to assess reflection-impulsivity in children between six and twelve years old, and is the one recommended by specialized bibliography. The assessment of personality was made by means of the Spanish adaptation of the Children's Personality Questionnaire, CPQ (Porter \& Cattell, 1979). Results obtained from a sample of 94 participants between eleven and twelve years old indicate the inexistence of correlation between the studied dimensions of personality and reflection-impulsivity. As hypothesized, the only consistent and significant relationships were those of the scale of mental ability in the CPQ, and the dimension dominant-submissive, both interpreted within the frame of cognitive styles. Obtained data support the theoretical validity of the reflection-impulsivity with an approach based on cognition, as well as the divergent validity of the MFFT-20 for a sample of Spanish children.
\end{abstract}

Key words: Cognitive styles, reflection-impulsivity, personality, MFFT-20, CPQ.

\section{RESUMEN}

En este trabajo se analiza la validez teórica del estilo cognitivo reflexividad-impulsividad a través de una aproximación basada en la cognición. Para ello, se ha analizado la relación entre este estilo cognitivo y la personalidad, usando para la evaluación de la reflexividad-impulsividad el The Matching Familiar Figures Test 20, MFFT-20 (Cairns \& Cammock, 1978). Este instrumento no ha sido empleado con tal propósito en la investigación previa, y esto a pesar de haberse constatado que se trata de la herramienta de evaluación con más garantías científicas para la evaluación de la reflexividad-impulsividad en niños de entre 6 y 12 años, y por lo tanto, la recomendada por los especialistas en esta área de trabajo. La evaluación de la personalidad se realizó a través de la adaptación española del Children's Personality Questionnaire, CPQ (Porter \& Cattell, 1979). Los resultados obtenidos a partir de una muestra de 94 participantes de entre 6 y 12 años ponen de manifiesto que la reflexividad-impulsividad y la personalidad son constructos independientes. Tal y como se predijo, las únicas relaciones significativas entre ambos aparecen para las subescalas de habilidad mental del CPQ, y la dimensión dominante-sumiso. Estos datos apoyan la validez teórica de la reflexividad-impulsividad conceptualizada a partir de una aproximación centrada en la cognición, al igual que la validez divergente del MFFT-20.

Palabras clave: Estilos cognitivos, reflexividad-impulsividad, personalidad, MFFT-20, CPQ.

Artículo recibido/Article received: Enero 27, 2009/January 27, 2009, Artículo aceptado/Article accepted: Mayo 7, 2009/May 7/2009

Dirección correspondencia/Mail Address: Hugo Carretero-Dios, Facultad de Psicología. Universidad de Granada. Departamento de Psicología Social y Metodología de las Ciencias del Comportamiento. Campus Cartuja s/n. 18071 - Granada (España). e-mail: hugocd@ ugr.es ; Macarena De los Santos-Roig, Facultad de Psicología. Universidad de Granada. Departamento de Psicología Social y Metodología de las Ciencias del Comportamiento. Campus Cartuja s/n. 18071 - Granada (España). E-mail: dlsantos@ugr.es ; Gualberto Buela-Casal, Facultad de Psicología. Universidad de Granada. Departamento de Personalidad Evaluación y Tratamiento Psicológico. Campus Cartuja s/n. 18071 Granada (España). E-mail: gbuela@ugr.es

International Journal of Psychological Research esta incluida en PSERINFO, Centro de Informacion Psicologica de Colombia, GOOGLE SCHOLARS y DIALNET. Algunos de sus articulos estan incluidos en Social Science Research Network y está en proceso de inclusion en diversas fuentes y bases de datos internacionales.

International Journal of Psychological Research is included in PSERINFO, Centro de Información Psicológica de Colombia, GOOGLE SCHOLARS and DIALNET. Some of its articles are included in Social Science Research Network, and it is in the process of inclusion in a variety of sources and international databases. 
The concept of cognitive style was put forward in the 1950's by personality researchers after the observation that people display distinctive and stable ways of solving intellectual problems, and the possibility of grouping such "modes of action" (García-Ramos, 1989). There are several trends in the description and account of cognitive styles that can be classified under three categories (Sternberg \& Grigorenko, 1997): personality-centered, which focuses cognitive styles as manifestations of dynamic intra-psychic variables, with a psychoanalytic slant (Gregorc, 1979); activity-centered, which conceives of cognitive styles as mediating variables related to the modes of action from personality to cognition; and a third and more empirically supported approach centered on cognition. This approach attempts to identify the characteristic manners people adopt in tackling intellectual problems. It does not rely upon intra-psychic variables nor mediating variables for other activities in daily life. Instead, this approach concentrates on the differences in cognitive functioning itself.

The cognitive style that has been more thoroughly studied is reflection-impulsivity (R-I) (Palacios, 1982; Servera, 1992). R-I is related to the ways in which subjects face tasks characterized by uncertainty. Impulsivity typifies quick answers to tasks and a high number of errors. Reflection applies to subjects that respond more slowly to tasks and commit few errors.

From this cognitive approach one can derive important theoretical implications. For one thing, it obtains validation from the "intellectual" sphere, for example academic performance or learning problems, while no association can be observed with other "non-cognitive" areas. Research on the relationship between R-I and academic performance or learning problems (Servera, 1990; Servera, 1992; Buela-Casal, Carretero-Dios \& De los Santos-Roig, 2000) have concluded consistently that the performance of impulsives is significantly poorer than that of reflexives and the former are prone to develop learning problems. Likewise, the convergent validity of R-I, within the cognitive framework, is related to other reasoning tasks characterized by uncertainty (Buela-Casal, De los SantosRoig \& Carretero-Dios, 2001) and has obtained a qualified support (Palacios, 1982).

Broadly, the data obtained by means of the main instruments for the assessment of R-I, the Matching Familiar Figures Test, MFFT (Kagan, 1965) or the Matching Familiar Figures Test 20, MFFT20 (Cairns \& Cammock, 1978, 1982), have provided support for the essential aspects of the scientific reliability of the reflection-impulsivity construct (Servera, 1992; BuelaCasal, Carretero-Dios \& De los Santos-Roig, 2001a, b; Buela-Casal, Carretero-Dios, De los Santos-Roig \& Bermúdez, 2003; Carretero-Dios, De los Santos-Roig \& Buela-Casal, 2008). Nevertheless, it should be stressed that from a theoretical perspective, R-I need not correlate with
Carretero-Dios, H, De los Santos-Roig, M., \& Buela-Casal, G. (2009). Role of the Matching Familiar Figures Test-20 in the Analysis of Theoretical Validity of the Reflection-Impulsivity: A Study with Personality. International Journal of Psychological Research, 2(1), 6-15.

other behavior or personality areas. This is to be taken into account by research because it is one of the arguments involved in discussions about the status of reflectionimpulsivity.

Regarding the relationship between R-I and other "independent" areas, the field that has drawn more attention has been that of personality. In this respect, the thorough revision made by Servera (1992) highlights the study by Block, Block, and Harrington (1974). These authors identified four groups on the basis of the mean of errors and latency in the MFFT, namely, impulsive, reflective, quickaccurate, slow-inaccurate. They found moderate correlations between latency and personality, and high correlations for errors. Since these authors had studied cognitive styles with a focus on personality they had expected such a relationship due to their notion of R-I, something consistent with their theoretical stance on personality. However, the latency variable, in their view, related to the style component (reflective or impulsive), should have displayed a closer relationship with personality. According to their interpretation, latency simply interacts with errors and should be taken as a variable in competence. They conclude that it is a capacity, rather than a cognitive style, that is measured. Late, Block, Gjerde, and Block (1986) replicated the study with similar results.

Also using the MFFT but with regression and correlation analyses, Victor, Halverson and Montague (1985) disagree with the classification of subjects made by Block's team because they did not find personality differences. However, the former group of researchers pointed out that in the slow-inaccurate group (again the accuracy component) correlates of impulsivity behavior were indeed observed, mainly for errors. We should note that cognitive, and behavioral or motor impulsivity (related to hyperactivity) are independent dimensions, as evaluated by the Eysenck's Personality Questionnaire (EPQ). Similarly, Cairns and Habirson (1975) did not find a relationship between reflection-impulsivity as evaluated by MFFT and personality evaluated by EPQ, including Eysenck's dimension of personality impulsivity. Glow, Lange, Glow y Barnett (1983) used the same personality questionnaire and did not observe any relationship between MFFT and personality either. Finally, Bentler and McClain (1976), did not find high correlations between errors and latency in MFFT, and personality, so they concluded that reflection-impulsivity obeys to situational variables rather than personality traits, an explanation consistent with a cognitive position.

Such disparities between the data obtained by Block's team and the rest of the researchers regarding the relationship between R-I and personality have been used, mainly by Block's group, to undermine the construct validity of R-I. Nevertheless, the position of Block's team 
with respect to cognitive styles is not based on cognition, but on intra-psychic personality variables, and this stance leads their interpretations and conclusions. With respect to the closer relationships observed in the error variable, less related to R-I according to Block's team, we should point out that, contrary to their opinion, the importance of latency and errors in R-I has been underscored since the earliest studies of R-I (Kagan \& Kogan, 1970). Impulsivity is always defined as a function of the interaction between both variables in tasks involving uncertainty. Consequently, the alleged contradiction in the basic conception of R-I vanishes.

Finally, we want to mention a ubiquitous problem in all studies, namely, the use of MFFT, and errors and latencies, separately. As Servera (1992, p. 73) puts it

“...as long as the MFFT keeps being used, it will not be possible to obtain a reliable validity index for $R-I \ldots$ attempting to determine the validity of $R-I$ on the basis of scores of errors and latencies separately does not obey to the original concept of $R$-I either".

Several studies have shown the low validity of the MFFT for measuring R-I (Egeland \& Weinberg, 1976; Messer \& Brondzinski, 1981) and argued against its use. On the contrary, its new version, the MFFT-20, has demonstrated its reliability as an instrument for evaluating R-I (Cairns \& Cammock, 1978, 1982; Servera, 1990, 1992; Buela-Casal, et al., 2001a, b; Buela-Casal, et al., 2003) and has lead to its widespread use to overcome the shortcomings in the MFFT. It is surprising that studies based on the earlier version of the test still predominate.

Drawing upon a theoretical stance based on cognition, the aim of the present study analyzes the validity of the R-I construct. The evaluating instrument employed is the Spanish adaptation of the MFFT-20 (Buela-Casal et al., 2003). Results will also be discussed in light of the divergent capacity of the MFFT-20. Thus, an inquiry will be made into the relationship between errors and latency in interaction, and personality, as formulated since the beginning of R-I. Previously, separate analyses of errors and latencies will be conducted in order to check the differences between both analyses. Such a study seems necessary in the absence of research on the relationship between R-I and personality by means of the MFFT-20. It has already been stressed that most studies have adopted the MFFT despite its serious psychometric shortcomings.

\section{METHOD}

\section{Participants}

The sample consisted of 94 students in their 6th year of primary education, from a school in a medium sized town in Andalusia (South of Spain). Mean age of the sample was 11.16 years old. Participants' ages ranged between 11 and 12 years of age with the following distribution: 69 boys (56 eleven-year-olds, 13 twelve-yearolds) 25 girls (15 eleven-year-olds, 10 twelve-year-olds).

\section{Instruments}

Matching Familiar Figures Test-20, MFFT-20. This is a perceptive matching test to be administered individually with an average duration between 15 to 20 minutes. It comprises of two sample items and 20 measure items. Every item includes a model drawing and six versions of it with only one exact reproduction of the model. The subject's task is to identify the option that matches the model. The subject can make six attempts. In the case that the subject does not select the correct option, he/she is told the correct option and is then passed on to the next item. The response latency for the first choice and the number of errors for each item are recorded. Upon finishing the test, the total number of errors and the mean response latency are recorded. The present study employed the Spanish adaptation of the test made by Buela-Casal et al. (2003). The formulation made by Salkind and Wright (1977) was used to obtain the normative data and provided continuous impulsivity and inefficiency scores. 1 scores (impulsivity) come from gross latencies and error scores, both transformed into typical scores. Thus, reflectionimpulsivity scores are obtained by the formula IS $=Z e i-$ $Z l i$, where $e i$ stands for error scores of the subject, and $l i$ stands for latencies. This formula is interpreted by considering that high positive values of $I$ (high number of errors and low latency) indicate impulsivity, and the reverse, high negative values of $I$ indicate reflection. The same formula is used for efficiency-inefficiency but both scores are added: IS $=Z e i+Z l i$. Negative typical scores in errors and latencies indicate efficiency; positive typical scores in errors and latencies indicate inefficiency. BuelaCasal and his team simplify the interpretation of scores by using decatypes. Thus, value 0 corresponds to extreme reflective or efficient subjects depending on the case, while value 10 indicates extreme impulsive or inefficient, the mean value represented by 5 (Buela-Casal et al., 2003).

Spanish Adaptation (Porter \& Cattell, 1995) of Children's Personality Questionnaire, CPQ (Porter \& Cattell, 1979). This questionnaire comprises 14 scales: 13 scales evaluate primary dimensions of personality and the remaining scale assesses mental ability. All the scales are conceived of in a bi-polar manner and total 140 items administered collectively in two forty-minute sessions approximately. The scales are: 1) Reserved-Open, 2) Low intelligence-High intelligence, 3) Affected by feelingsEmotionally stable, 4) Calm-Excitable, 5) SubmissiveDominant, 6) Sober-Lively, 7) Careless-Conscientious, 8) Inhibited-Enterprising, 9) Weak sensitivity-Strong sensitivity, 10) Assured-Doubtful, 11) Ingenious-Simple, 
12) Serene-Apprehensive, 13) Less integrated-More integrated, 14) Relaxed-Tense. The independence of the different dimensions of personality evaluated has been sufficiently contrasted, and so have its validity and reliability (Porter \& Cattell, 1979; Porter \& Cattell, 1995). The evaluation of personality by means of the CPQ was conducted prior to the R-I. The test was administered collectively according to the test's standards.

\section{Procedure}

A revision made by Messer (1976) cites several studies showing that, due to their content, responses to the MFFT and MFFT-20 are influenced if another test is administered at the same time. So, when the evaluation of R-I follows other tests (in studies with intelligence tests) the reflective response increases as compared to an earlier evaluation of R-I. For this reason, in our study the evaluation of reflection-impulsivity was conducted fifteen days after the evaluation of personality. Consequently, a first stage of training in the use of MFFT-20 took place before the actual gathering of data. There were four evaluators (two male, two female). Previous to the evaluation itself, evaluators were introduced to the subjects by class teachers, and the evaluation was announced. Children were assigned to evaluators randomly. In every class, children were allocated into the four groups following alphabetical order. Once evaluators had been assigned their groups, they devoted some minutes to establish rapport. Later on, children gave their personal details and the procedure for evaluation was explained following the test's standard instructions. This was followed by the completion of the two sample items and the evaluation itself was conducted.

\section{Statistical analyses}

Three types of analyses have been performed:

Correlation analyses. Like the studies cited in the Introduction, Pearson's correlation analyses were made between the two variables that control R-I through the MFFT-20, and the direct score in every personality dimension in the CPQ. Despite our reservations concerning the isolation of scores, the novelty of using the improved MFFT-20 requires the repetition of these analyses for comparison with previous studies. We obtained the determination coefficient and the corrected coefficient so that, in case of obtaining significant data, we could determine the degree of variance accounted for.

Regression analyses. Regression analyses were performed at every stage using the resulting scores in Impulsivity and Inefficiency as independent variables following Salkind and Wright (1977). Regression data are shown with a minimum significance of value $p<.05$.
Carretero-Dios, H, De los Santos-Roig, M., \& Buela-Casal, G. (2009). Role of the Matching Familiar Figures Test-20 in the Analysis of Theoretical Validity of the Reflection-Impulsivity: A Study with Personality. International Journal of Psychological Research, 2(1), 6-15.

T contrasts: $t$ independent contrasts will be carried out for each one of the personality dimensions between "exacts" (reflexive and fast-exacts) and "inexacts" (impulsive and slow-inexact) in order to estimate if the differences that appear between both are greater than those that the reflexives demonstrate as opposed to the impulsives. This will help to clarify the importance of exactness (accuracy) as compared to style. This is the same procedure as used in the Block group, except that in the present study the groups are not formed by means of a division between the reference groups' error and latency medians, yet by the Buela-Casal, et al. (2001b) Spanish scaling of the MFFT-20. This scaling is based on the Salkind and Wright formulation (1977) and allows us to obtain the impulsivity and inefficiency scores (see instruments section) in considering the latency and error interaction. This interaction, as was mentioned in the introduction, is of great importance according to R-I basic conceptualisation. Therefore, the groups formed from the decatype scores for impulsivity and inefficiency were: Impulsives (scores greater than 5 in Impulsivity and in Inefficiency), fast-exact or Impulsive-Efficient (greater than 5 in impulsivity and equal or less than 5 in inefficiency), and slow-inexact or Reflexive-Inefficient (less than or equal to 5 in Impulsivity and greater than 5 in Inefficiency).

\section{RESULTS}

Table 1 shows the data obtained in correlation analyses made of the dimensions studied. It should be noted that correlations between the variables that operate R-I through the MFFT-20 and the 14 dimensions evaluated by the CPQ are almost inexistent. So, although the error variable displays higher values than the latency variable in most cases, errors show low correlation, with statistical significant reached in emotionally stable-affected by feelings $(-.35, p<.05$, accounting for $11 \%$ of the variance for this dimension of personality), dominance-submission $(-.24, p<.05$, accounting for $4 \%$ of the variance for this dimension of personality), enterprising-inhibited $(-.26, p<$ .05 , accounting for $6 \%$ of the variance), apprehensiveserene $(.25, p<.05$, accounting for $5 \%$ of the total variance), and the high value obtained for high intelligencelow intelligence $(-.51, p<.01$, accounting for $25 \%$ of the total variance of the said dimension). It is needless to say that the data obtained in the dimension high intelligencelow intelligence are remarkable although they relate to a scale of mental ability rather than a personality trait proper.

Concerning the latency variable, only one significant datum $(p<.05)$ was obtained for the dimension dominance-submission with a correlation of .26 , which accounts for $5 \%$ of variance for this dimension. As can be 
Table 1. Correlation analyses between errors and latency in the MFFT-20 and the 14 dimensions of personality in the $C P Q$

\begin{tabular}{|c|c|c|c|c|c|c|}
\hline & \multicolumn{3}{|c|}{ Errors } & \multicolumn{3}{|c|}{ Latency } \\
\hline & $R$ & $R^{2}$ & $R^{C}$ & $R$ & $R^{2}$ & $R^{C}$ \\
\hline Open-Reserved & -.15 & .02 & .01 & .14 & .02 & .01 \\
\hline High intelligence-Low intelligence & $-.51 * *$ & .26 & .25 & .21 & .05 & .03 \\
\hline Emotionally stable-Affected by feelings & $-.35^{*}$ & .12 & .11 & .17 & .03 & .01 \\
\hline Excitable-Calm & .03 & .00 & .00 & .03 & .00 & .00 \\
\hline Dominant-Submissive & $-.24 *$ & .06 & .04 & $.26 *$ & .07 & .05 \\
\hline Lively-Sober & .01 & .00 & .00 & .00 & .00 & .00 \\
\hline Conscientious-Careless & -.04 & .00 & .00 & -.08 & .00 & .00 \\
\hline Enterprising-Inhibited & $-.26 *$ & .07 & .06 & .19 & .03 & .02 \\
\hline Weak sensitivity-Strong sensitivity & .12 & .01 & .00 & -.20 & .04 & .03 \\
\hline Doubtful-Assured & .15 & .02 & .00 & -.03 & .00 & .00 \\
\hline Ingenious-Simple & .05 & .00 & .00 & .00 & .00 & .00 \\
\hline Apprehensive-Serene & $.25^{*}$ & .06 & .05 & -.17 & .03 & .02 \\
\hline Less integrated-More integrated & -.03 & .00 & .00 & .02 & .00 & .00 \\
\hline Tense-Relaxed & .19 & .03 & .02 & -.02 & .00 & .00 \\
\hline
\end{tabular}

seen, this dimension correlates with errors significantly.

In what follows, regression analyses are made with impulsivity or inefficiency as independent variables. As explained in the section statistical analyses, data are considered significant for values $p<.05$. Thus, inefficiency is not related significantly to any personality dimension. In regression analyses, only two dimensions out of the fourteen scales are related to impulsivity in a significant manner. These dimensions are high intelligence-low intelligence, and dominant-submissive. Table 2 presents the data obtained in the regression analyses made with impulsivity as independent variable and the dimensions high intelligence-low intelligence, and dominant-submissive as dependent variables.

Table 2. Regression analyses for values in Impulsivity as predictor of direct scores in personality dimensions high intelligence-low intelligence and dominant-submissive in the CPQ

\begin{tabular}{|c|c|c|c|c|c|c|c|}
\hline & \multicolumn{3}{|c|}{$\begin{array}{l}\text { Summary of } \\
\text { regression }\end{array}$} & \multicolumn{4}{|c|}{ Coefficients } \\
\hline & $R$ & $R^{2}$ & $R^{C}$ & $B$ & Beta & $T$ & $p$ \\
\hline High intelligence-Low intelligence & -.39 & .15 & .14 & -.35 & -.39 & -3.65 & .00 \\
\hline Dominant-Submissive & -.31 & .10 & .08 & -.37 & -.31 & -2.78 & .00 \\
\hline
\end{tabular}

Note: $R$ : Correlation coefficient. $R^{2}$ : Determination coefficient. $R^{c}$ : Corrected determination coefficient. 
The predictive capacity of errors and latency taken together in a single score, impulsivity or inefficiency, decreases notably. In the case of inefficiency, it does not predict significantly any dimension of personality. For impulsivity, Table 2 provides significant values in two dimensions for $p<.01$. For dimension high intelligence-low intelligence, there is a correlation of -.39 and this accounts for $14 \%$ of variance, and for dimension dominantsubmissive, correlation is -.31 and this represents $8 \%$ of variance. One should remember that the dimension high intelligence-low intelligence is the one that displayed the strongest relationship with errors in correlation analyses (-.51). It is also noticeable that the dimension dominantsubmissive was the only one significantly correlated to the two variables that operate impulsivity: errors and latency.

In performing the analysis of the importance of the R-I cognitive style "exactness" or efficiency-inefficiency (Salkind \& Wright, 1977), in relating it to the personality, and as was explained in the statistical analysis section, the same procedure used by the Block group $(1974 ; 1986)$ was followed. The objective was to observe if the main personality differences between participants are in function of the exactness (efficiency-inefficiency) or in function of the style (reflexivity-impulsivity), since as was pointed out by the Block group, the "exactness" differs by greater measure in those participants within the R-I cognitive style. Table 3 shows the data for the contrasts made between reflexives and impulsives in each of the personality dimensions. Table 4 shows the data of the mean contrasts obtained for the two participant groups formed from the efficiency-inefficiency variable or exactness.

When the reflexive group is contrasted to the impulsive group, in which there appear significant differences when $p<.05$, the dimensions are the same (high intelligence-low intelligence and dominant-submissive). However, in the regression analyses they were significantly aforementioned in considering the impulsivity value (Table 2).

In the case of the "exact" subjects as opposed to the "inexact" participants, appear two personality dimensions that differentiate the two groups, excitable-calm and apprehensive-serene when $p<.05$. There are no statistically significant differences for the remaining 12 dimensions.

\section{DISCUSSION}

The present research has not obtained a generalized relationship between the cognitive style R-I and personality as hypothesized from a cognition-based perspective. Significant relationships between R-I and personality were indeed found in every analysis but only for the dimension dominant-submissive and the scale of mental ability high intelligence-low intelligence, discussed below.
Carretero-Dios, H, De los Santos-Roig, M., \& Buela-Casal, G. (2009). Role of the Matching Familiar Figures Test-20 in the Analysis of Theoretical Validity of the Reflection-Impulsivity: A Study with Personality. International Journal of Psychological Research, 2(1), 6-15.

A stronger relationship between the variable error and personality has been corroborated, since the connection with latency has been inexistent. However, this was not the goal of the present study. A cognition-centered approach to cognitive styles focuses on the interaction between both variables, latency and errors, given the single value assigned to impulsivity, which combines errors and latency (Kagan \& Kogan, 1970). One of the aims was to check the differences observed in the analyses when both variables were taken separately or together in a single score. As expected, combining the variables in the MFFT-20 results in an absence of correlation with the value of impulsivity (emotionally stable-affected by feelings, enterprisinginhibited, apprehensive-serene). In earlier studies, these variables had been significantly correlated with either errors or latency. It should be noted that research on the cognitive style R-I should target the interaction between variables (Servera, 1992), not only because results differ in either case, as seen in our data, but because detaching the variables produces an important theoretical bias (Kagan \& Messer, 1975)

The studies carried out by Block et al. (1974, 1986) argue that differences observed among subjects should be greater by "isolating" the "accuracy" component, or efficiency-inefficiency, in order to single out "accurate" from "inaccurate" subjects. These results, obtained by Block's team, are not confirmed by the present study. The application of regression and $t$ analysis with efficiencyinefficiency as an independent variable did not produce statistically significant predictions of any dimension of personality.

It is relevant to remark, and necessary to explain, that regression analyses with impulsivity as an independent variable have related two variables with R-I consistently: the personality dimension dominant-submissive, and the scale of mental ability high intelligence-low intelligence.

With respect to this scale of mental ability, the results obtained provide further support to a cognitioncentered approach to R-I. We have repeatedly stressed that, from this perspective, reflection-impulsivity should demonstrate a strong influence on intellectual performance, solving intellectual tasks. This is a constant finding in similar studies (Servera, 1990, 1992; Buela-Casal, et al., 2000). The scale high intelligence-low intelligence is not a measure of intelligence as such, in the manner of the I.Q. (Porter \& Cattell, 1995). Instead, it evaluates the subjects' ability to understand abstract relationships (Porter \& Cattell, 1979). It goes without saying that reflectionimpulsivity should have a bearing on such type of scale, in fact this is one of our findings.

What is measured by the scale high intelligencelow intelligence is mental ability, rather than intelligence through the I.Q. The cognitive style R-I, as evaluated by the MFFT-20 should not display many connections with the 
Table 3. $T$ contrasts between reflexives and impulsives for each one of the CPQ personality dimensions.

\begin{tabular}{lcccc}
\hline & \multicolumn{2}{c}{$N=31$} & \multicolumn{3}{c}{$N=16$} \\
& \multicolumn{2}{c}{ REFLEXIVES } & \multicolumn{2}{c}{ IMPULSIVES } \\
& \multicolumn{2}{c}{ Slow-efficient } & & \multicolumn{2}{c}{ Fast-inefficient } \\
& 7.12 & 1.56 & 6.55 & $S D$ \\
\hline Open-Reserved & 9.20 & 0.97 & 7.66 & 1.87 \\
High intelligence-Low intelligence * & 7.50 & 1.65 & 6.11 & 2.31 \\
Emotionally stable-Affected by feelings & 3.70 & 2.29 & 4.77 & 2.04 \\
Excitable-Calm & 5.42 & 2.09 & 4.00 & 1.41 \\
Dominant-Submissive * & 5.25 & 1.82 & 5.22 & 1.39 \\
Lively-Sober & 7.25 & 2.04 & 6.66 & 2.39 \\
Conscientious-Careless & 6.08 & 1.95 & 4.55 & 2.06 \\
Enterprising-Inhibited & 2.95 & 2.15 & 4.00 & 1.93 \\
Weak sensitivity-Strong sensitivity & 4.29 & 1.62 & 5.44 & 1.81 \\
Doubtful-Assured & 2.95 & 1.89 & 2.66 & 1.50 \\
Ingenious-Simple & 2.66 & 2.01 & 4.07 & 2.58 \\
Apprehensive-Serene & 6.29 & 2.29 & 6.11 & 1.36 \\
Less integrated-More integrated & 3.79 & 1.53 & 5.11 & 2.02 \\
Tense-Relaxed & & & &
\end{tabular}

Note: $* p<.05$.

Table 4. $T$ contrasts between "exacts" and "inexacts" for each one of the CPQ personality dimensions.

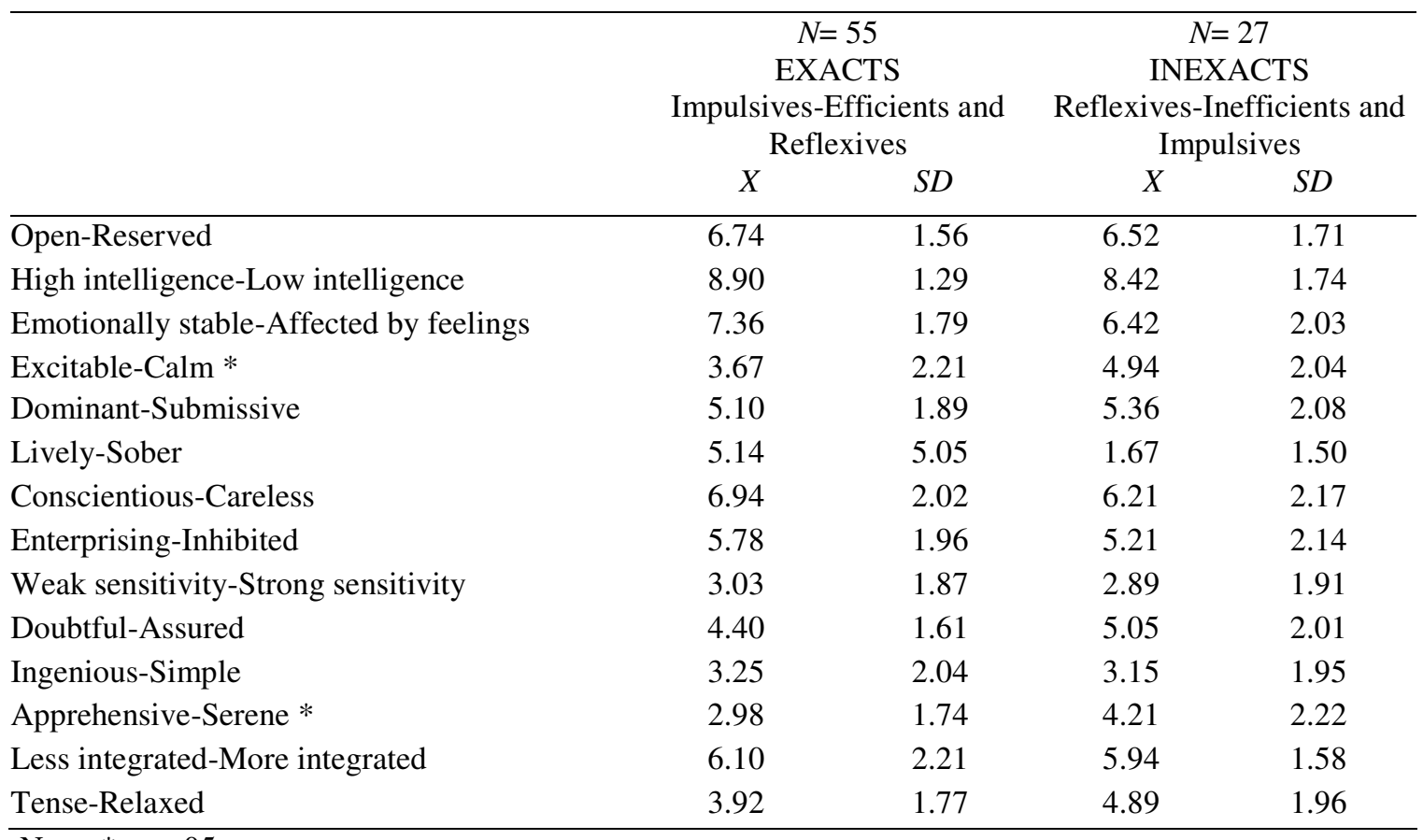

Note: $* p<.05$. 
Carretero-Dios, H, De los Santos-Roig, M., \& Buela-Casal, G. (2009). Role of the Matching Familiar Figures Test-20 in the Analysis of Theoretical Validity of the Reflection-Impulsivity: A Study with Personality. International Journal of Psychological Research, 2(1), 6-15. measures of the I.Q. (Ziegler, 1963), because this would make it another measure of intelligence, not an independent dimension. This is so in the conceptual argumentation behind this study, already dealt with in the introduction. There are abundant studies of the interactions of R-I, including the fields of intelligence and personality. Previous studies have inquired into the discreteness and identity of the cognitive style R-I and the present study offers further evidence in this respect. Regarding the relationship with the I.Q., contrary to personality, available data are leading researchers to agree upon the fact that the relationship between R-I and intelligence has only a moderate presence (.30) when the content of the intelligence test includes uncertainty in the answers, the critical element for R-I. When uncertainty is absent from the tests, the relationship disappears (Buela-Casal et al. 2001). To sum up, the findings for the scale high intelligence-low intelligence support the theoretical stance maintained by Kagan.

Considering the other related scale, dominantsubmissive, the explanation is more complex and involves cultural factors previously observed (Buela-Casal, Carretero-Dios, De los Santos-Roig \& Bermúdez, 2000). In the present study, the personality dimension dominantsubmissive has been connected negatively with errors ($.24)$, positively with latency (.26), and negatively with the interaction between errors and latencies, that is, a greater impulsivity shows either a submissive trait in the subject or a more active, dogmatic or dominant trait (Porter \& Cattell, 1979; Porter \& Cattell, 1995). In this respect, several authors have pointed at "docility" or "acceptance of values" as the key to developing an impulsive or reflective answer. As Salkind and Wright (1977 p. 386) put it, the educational system favours exactness more than velocity, therefore favouring reflexivity over impulsivity. In particular, the children who are more mature, more culturally and socially conscientious, and whose values are more typical of the majority of the culture, should be those who demonstrate a greater efficiency and opt for the exactness and precision more than quickness. Yet, these same children should also demonstrate themselves as being particularly reflexive for their age. They should not be surprised at doing things that are highly valued by the majority of the culture, including a change in style or strategy in order to suit the specific task demands that they are presented with.

Our results provide a partial support for Salkind and Wright's theoretical postulates since the only dimension of personality that distinguishes reflective from impulsive subjects when means were contrasted was dominant-submissive. It was shown that reflective subjects tend to submission and docility. The question then is: does dominance lead to impulsivity, or does impulsivity, because of its consequences for the subject, lead to a manipulative and dominant attitude? Or rather, does docility and social submission lead to a type of reflective response because that is what society demands, or do the consequences obtained by the subject upon using a reflective strategy conduce to a more submissive behavior? We cannot provide answers to such questions as yet. "There is still no available theoretical framework to group together the great amount of experimental data about cognitive styles" (Servera, 1992 pp. 11). Such crude statement about cognitive styles in general correctly applies to present results about reflection-impulsivity. Our study has proved that the relationships between R-I and personality are inexistent, as Kagan's team hypothesized. When such relationships are observed, they can be explained within the cognitive-based framework. Nevertheless, previous results, as different as controversial, can only allow tentative conclusions. Research aimed at clarifying whether cognitive styles should be considered independent variables such as intelligence, personality, social adaptation, motor impulsivity, and the like, is necessary.

Contradictions, which seem to characterize this type of studies, seem to arise from theoretical positions (cognition, activity or personality-based), from different experimental designs, or even the evaluating instrument (MFFT or MFFT-20 in the case of R-I). As Sternberg and Grigorenko (1997) point out, a consequence of the multiplicity of results and conclusions is the decrease in the amount of research on cognitive styles during the last decade. In this regard, the title of the theoretical work by Sternberg and Grigorenko and published by American Psychologist is significative: Are Cognitive Styles Still in Style? (Sternberg \& Grigorenko, 1997). Considering the said discrepancies, these authors ask the reader about such web-known area of cognitive styles as academic performance: "How many constructs show correlations with school achievement that differ by close to .90 in two different schools, that are statistically significant in opposite directions, and that differ significantly from each other as well?" (Sternberg \& Grigorenko, 1997, pp. 700). However, and we subscribe this opinion, this diversity of results calls for further studies to complete much-needed research. We can conclude with Sterngberg and Grigorenko's words:

"Fashions come and go. In recent years, styles have been relatively out of fashion because of some mixed results in internal and external validations. Commercialism in the pushing of specific theories and programs also may have led to distaste on the part of some scientists. But we believe that styles have served and can continue to serve an important interface at the border between personality and cognition, a border that has been and continues to be an important one. Like wide neckties, styles may come and go, 
but they never will go completely out of style." (Sternberg \& Grigorenko, 1997 p. 710).

\section{REFERENCES}

Bentler, P.M., \& McClain, J. (1976). A multitraitmultimethod analysis of reflection-impulsivity.Child Development, 47, 218-226.

Block, J., Block, J.H., \& Harrington, D.M. (1974). Some misgivings about the Matching Familiar Figures Test. Developmental Psychology, 10, 611-632.

Block, J., Gjerde, P.F., \& Block, J.H. (1986). More misgivings about the Matching Familiar Figures Test as a measure of reflection-impulsivity: Absence of construct validity in preadolescence. Developmental Psychology, 22, 820-831.

Buela-Casal, G., Carretero-Dios, H. \& De los Santos-Roig, M. (2000). Reflexividad frente $a$ impulsividad en el rendimiento académico: un estudio longitudinal. [Reflexivity vs. Impulsivity in academic performance: a longitudinal study]. Análisis y Modificación de Conducta, 26, 555-583.

Buela-Casal, G., Carretero-Dios, H., \& De los Santos-Roig, M. (2001a). Consistencia longitudinal de la Reflexividad-Impulsividad evaluada por el Matching Familiar Figures Test-20 (MFFT-20). [Longitudinal consistency of reflexivity-impulsivity evaluated by the MFFT-20]. Clínica y Salud, 12, 51-70.

Buela-Casal, G., Carretero-Dios, H., \& De los Santos-Roig, M. (2001b). La reflexividad-impulsividad como una dimensión continua: validación del sistema de clasificación de Salkind y Wright (1977) [Reflexivityimpulsivity as a continuous dimension: validation of Salkind and Wright's classification model (1977)]. Revista Latinoamericana de Psicología, 33, 149-157.

Buela-Casal, G., Carretero-Dios, H., De los Santos-Roig, M., \& Bermúdez, M.P. (2000). ReflexividadImpulsividad en niños españoles y estadounidenses: un estudio transcultural. [Reflection-Impulsivity in Spanish and American children: a trans-cultural study] Clínica y Salud, 11, 15-33.

Buela-Casal, G., Carretero-Dios, H., De los Santos-Roig, M. \& Bermúdez, M.P. (2003). Psychometric properties of a Spanish adaptation of the Matching Familiar Figures Test 20, MFFT20. European Journal of Psychological Assessment, 19, 151-159.

Buela-Casal, G., De los Santos-Roig, M., \& Carretero-Dios, H. (2001). La Reflexividad-Impulsividad y la Inteligencia: un estudio de la validez teórica del estilo cognitivo y de la validez divergente del MFFT-20. [Reflection-impulsivity and intelligence: a study of the theoretical validity of cognitive style and the divergent validity of the MFFT-20]. Revista Mexicana de Psicología, 19, 155-166.
Carretero-Dios, H, De los Santos-Roig, M., \& Buela-Casal, G. (2009). Role of the Matching Familiar Figures Test-20 in the Analysis of Theoretical Validity of the Reflection-Impulsivity: A Study with Personality. International Journal of Psychological Research, 2(1), 6-15.

Cairns, F.D., \& Cammock, J. (1978). Development of a more reliable version of the Matching Familiar Figures Test. Developmental Psychology, 5, 555-560.

Cairns, F.D., \& Cammock, J. (1982). Preliminary norms for the MFF20. Unpublished document

Cairns, F.D., \& Habirson, J.I. (1975). Impulsivity: selfreport and performance measures. British Journal of Educational Psychology, 45, 327-329.

Carretero-Dios, H., De los Santos-Roig, M., \& Buela-Casal, G. (2008). Influence of the difficulty of the Matching Familiar Figures Test-20 on the assessment of reflection-impulsivity: an item analysis. Learning \& Individual Differences, 18, 505-508.

Egeland, B., \& Weinberg, R.A. (1976). The Matching Familiar Figures Test: A look to its psychometric credibility. Child Development, 47, 483-491.

García-Ramos, J.M. (1989). Los estilos cognitivos y su medida: estudios sobre la dimensión dependenciaindependencia de campo. [Cognitive Styles and their measure: Studies on the Dimension DependencyIndependency of Field] Madrid: CIDE.

Glow, R.A., Lange, R.V., Glow, P.H., \& Barnett, J.A. (1983). Cognitive and self-reported impulsiveness: Comparison of Kagan's MFFT and Eysenck's EPQ impulsiveness measures. Personality and Individual Differences, 4, 179-187.

Gregorc, A.F. (1979). Learning/teaching styles: Potent forces behind them. Educational Leadership, 36, 234236.

Kagan, J. (1965). Matching Familiar Figures Test. Cambridge: Harvard University.

Kagan, J., \& Kogan, N. (1970). Individual variation in cognitive processes. En P. Mussen (Ed.), Carmichael's Manual of Child Psychology. (vol. 1). New York: Wiley.

Kagan, J., \& Messer, S.B. (1975). A reply to "some misgivings about de Matching Familiar Figures test as a measure of reflection-impulsivity". Developmental Psychology, 11, 244-248.

Messer, S.B. (1976). Reflection-impulsivity: A review. Psychological Bulletin, 83, 1026-1052.

Messer, S.B., \& Brondzinsky, D.M. (1981). Three year stability of reflection.impulsivity in young adolescents. Developmental Psychology, 17, 848-850.

Palacios, J. (1982). Reflexividad-impulsividad. Infancia y Aprendizaje, 17, 29-69.

Porter, R.B., \& Cattell, R.B. (1979). Handbook for the Children's Personality Questionnaire. Champaign, III: Institute for Personality and Ability Testing, Inc.

Porter, R.B., \& Cattell, R.B. (1995). CPQ: cuestionario de personalidad para niños. [CPQ: Children's Personality Questionnaire]. Madrid: TEA Ediciones

Salkind, N.J., \& Wright, J.C. (1977). The Development of Reflection-Impulsivity and Cognitive Efficiency (An 
Integrated Model). Human Development, 20, 377-387.

Servera, M. (1990). L'estil cognitiu reflexivitat-impulsivitat

i la seva relació amb variables de rendimient $i$ conducta

a l'infant. [The cognitive style reflection-impulsivity and its relationship to the variables of academic performance and behavior in children]. Unpublished M.A. thesis. Universidad de las Islas Baleares, Palma, Spain.

Servera, M. (1992). La modificación de la reflexividadimpulsividad y el rendimiento académico en la escuela a partir del enfoque de la instrucción en estrategias cognitivas. [The modification of reflection-impulsivity and academic performance in school. An approach to instruction in cognitive strategies]. Unpublished doctoral dissertation. Universidad de las Islas Baleares, Palma, Spain.

Sternberg, R.J., \& Grigorenko, E.L. (1997). Are Cognitive Styles Still in Style?. American Psychologist, 52, 700712.

Victor, J.B., Halverson, CH.F., \& Montague, R.B. (1985). Relationship between reflection-impulsivity and behavioral impulsivity in pre-school. Developmental Psychology, 21, 141-148.

Zigler, E. (1963). A measure in search of a theory. Contemporary Psychology, 8, 133-135. 